\title{
Kewenangan Dinas Kebudayaan Provinsi Riau Dalam Perlindungan Cagar Budaya Masjid Jami’ Air Tiris
}

\author{
1Nina Yuslaini, ${ }^{2}$ Dita Fisdian Adni \\ 12 Dosen Ilmu Pemerintahan Fakultas Ilmu Sosial dan Ilmu Politik Universitas Islam Riau \\ e-mail: ninayuslaini@soc.uir.ac.id
}

\begin{abstract}
Abstrak
Cagar Budaya merupakan kekayaan budaya bangsa sebagai wujud pemikiran dan perilaku kehidupan manusia yang penting artinya sebagai pemahaman dan pengembangan sejarah ilmu pengetahuan dan kebudayaan.Didalam peraturan Daerah Provinsi Riau Nomor 15 Tahun 2013 Tentang Pelestarian Cagar Budaya yaitu keberadaan Cagar Budaya di wilayah Provinsi Riau namun masalahnya belum mengembangkan dan menerapkan kebijakan yang dapat menjamin terlindunginya cagar budaya Mesjid Jami' Air Tiris menjadi tanggungjawab bersama.dan tujuan penelitian ini adalah untuk mengetahui bagaimana Kewenangan Dinas Kebudayaan Provinsi Riau dalam Perlindungan Cagar Budaya Mesjid Jami” Air Tiris. metode penelitian kualitatif pendektan deskriptif,Hasil penelitian ini menunjukkan bahwa Kewenangan Dinas Kebudayaan Provinsi Riau mempunyai tiga aspek penting dalam perlindungan cagar budaya Mesjid Jami' Air Tiris yaitu aspek atribusi,delegasi dan mandat.
\end{abstract}

Kata Kunci : Kewenangan,Cagar Budaya,Perlindungan

\begin{abstract}
Cultural Heritage is the nation's cultural wealth as a form of thought and behavior of human life which is important as an understanding and development of the history, science and culture. In Riau Province Regional No. 15 of 2013 concerning Cultural Heritage Preservation, namely the existence of Cultural Heritage in Riau Province, but the problem is not yet developing and implementing policies that can ensure the protection cultural heritage of the Jami 'Air Tiris Mosque is shared responsibility. and the purpose of this research is to find out how the authority culture of the Riau Province in the Protection of the Jami Mosque "Air Tiris Cultural Heritage. descriptive qualitative research method. The results of this study indicate that the authority of the Riau Province Cultural Service has three important aspects in the protection of the cultural heritage of the Jami 'Air Tiris Mosque namely, aspects of attribution, delegation and mandate.
\end{abstract}

Keywords: Authority, Cultural Heritage, Protection 


\section{PENDAHULUAN}

Undang-undang Nomor 23 Tahun 2014 tentang Pemerintah Daerah dalam pasal 1 ayat (1) bahwa Pemerintah Daerah terdiri atas urusan pemerintah absolut yaitu urusan pemerintahan yang urusan pemerintahan pusar dan Provinsi serta daerah KAbupaten Kota yang diserahkan kepada daerah sebagai pelaksana otonomi daerah. Menurut Undang-undang Republik Indonesia Nomor 11 Tahun 2010 Cagar Budaya merupakan kekayaan BUdaya sebagai wujud pemikiran dan perilaku kehidupan manusia yang terpenting dalam pemahaman dan pengembanagn dalam sejarah, ilmu pengetahuan, kebudayaan dalam masyarakat ,berbangsa dan bernegara, sehingga ini sangat perlu dilestarikan dan dikelola secara tepat melalui perlindungan, pengembangan, juga pemanfaatan dalam rangka memajukan kebudayaan secara nasional untuk kemakmuran rakyat. Benda cagara Budaya merupakan benda alam atau benda manusia,bergerak maupun tidak bergerak,berupa kesatuan atau kelompok,bagian-bagian,sisa-sisanya yang masih memiliki hubungan erat dengan kebudayaan dan juga sejarah perkembangan manusia.

Tugas dari pemerintahan daerah adalah melakukan perlindungan, pengembangan, pemanfaatan warisan Budaya dan Cagar Budaya. Sifat dari Cagar Budaya tersebut seperti rapuh,unik, langka, terbatas, juga tidak bisa diperbaharui. Sifat ini menyebabkan berkurangnya jumlah Cagar Budaya sebagai akibat dari pemanfaatan yang tidak diperhatikan seperti perlindungannya, meskipun batas usia 50 tahun sebagai titik tolak dalam penetapan status "kepurbakalaan", objek ini secara bertahap menempatkan benda,bangunan struktur lama menjadi Cagar Budaya baru. Cagar Budaya juga dapat digantikan dengan pemanfaatan yang sifatnya berkelanjutan (sustainable) ahar dapat dinikmati kehadirannya oleh generasi mendatang. Dalam Peraturan Daerah Provinsi Riau Nomor 15 Tahun 2013 pada pasal (6) tentang wewenang Cagar Budaya sebagai berikut: Pemerintah Daerah dalam melakukan pelestarian Cagar Budaya A.Membentuk Dewan Warisan Budaya B.Membentuk Tim ahli Cagar Budaya C.Menerima dan mendaftarkan, lokasi Budaya yang berada di darat dan di air yang mengandung Benda Cagar Budaya, Bangunan Cagar Budaya, dan struktur Cagar Budaya D. Menetapkan etika pelestarian Cagar Budaya E. Mengkoordinasikan pelestarian Cagara Budaya dan sebagai Cagar Budayalintas sector F.Menghimpun data warisan BUdaya dan Cagar Budaya G. Menetapkan peringkat Cagar Budaya H. Menetapkan dan mencabut status Cagar Budaya I.Membuat peraturan pengelolaan warisan Cagar Budaya J.Menyelenggarakan kerjasama pelestarian warisan budaya dan cagar Budaya K. Upaya pelestarian dapat dilaksanakan dalam tiga kegiatan utama yaitu pelindungan, pengembangan, dan pemanfaatan. Pada Perda Provinsi Riau Nomor 15 Tahun 2013 (Pasal 38) bagian Kelima yaitu tentang Pelindungan, siapa saja bias berberan serta melakukan perlindungan Cagar Budaya. Pengertian perlindungan adalah mencegan dan menanggulangi dari berbagai kerusakan, kehancuran dan kemusnahan dengan cara penyelamatan, pengamanan, zonasi, pemeliharaan dan pemugaran warisan Budaya dan Cagar Budaya.

Untuk melestarikan Cagar Budaya negara harus bertanggungjawab dalam pengaturan perlindungan, pengembangan, dan pemanfaatan Cagar Budaya. Cagar Budaya yaitu berbentuk benda, bangunan, struktur, situs, dan kawasan perlu dikelola oleh pemerintah dan pemerintah daerah dengan meningkatkan peran serta masyrakat untuk melindungi, mengembangkan dan memanfaatkan Cagar Budaya. Untuk mengingat kesadaran masyarakat merubah paradigm pelestarian Cagar Budaya harus memperhatikan keseimbangan aspek ideologis, akademis, ekologis, dan ekonomi untuk meningkatkan kesejahteraan social masyarakat. Partisipasi masyarakat dalam pelestarian warisan Cagar Budaya menjadin salah satu prioritas yang harus dicapai dalam setiap kegiatan pemanfaatan benda cagar budaya yang dilestarikan. Hal ini tentu berdampak dari kesadaran masyarakat akan pentingnya keberadaan bangunan Cagar Budaya, peran masyarakat terutama pada tokoh masyarakat adat sekitar sangat besar dalam pelestarian Cagar Budaya.

Dimulai dari ikut serta dalam hal pencarian cagar budaya, melindungi, melaporkan dan mendaftarkan cagar budaya yang dimiliki atau diketahuinya, ikut serta memelihara dan menjaga agar 
cagar budaya tersebut tidak rusak dan musnah Terdapat 39 cagar budaya benda tak bergerak. Penetapan itu sebagai bentuk kepedulian Pemprov Riau mempertahankan cagar budaya yang ada diseluruh kabupaten/kota.Mesjid Jami' ini juga masih digunakan oleh masyarakat sekitar mulai dari sholat lima waktu, rapat-rapat atau musyawarah keagamaan, musyawarah desa, memperingati hari-hari besar lainnya.

Dalam menunaikan badah sholat lima waktu sehingga kebersihan nya selalu terjaga serta bagunannyapun identik dengan keasliannya yang terbuat dari kayu pilihan yang tidak mudah lapuk namun sayangnya sentuhan renovasi dari pemerintah terkait sangat sedikit sekali itupun kendala masyarakat sekitar harus membuat proposal mengenai bangunan menjid tersebut barulah dana itu cair dan dapat digunakan untuk merenoavsi .

Sehingga kendala bangunan mesjid Jam'i air tiris ini cat nya sudah agak memudar dan terdapat cat mesjid ada yang terkikis didinding-dinding tampak terlihat juga bangunan tua yang butuh perhatian pemerintah agar dapat tetap terawat dan terlestari untuk ribuan tahun kedepan. Adapun jumlah pengunjung diperkirakan 50 orang perbulan dan rata-rata perhari itu lebih kuraang 10 orang biasanya pengunjung datang juga hari-hari tertentu seperti hari libur dan hari besar islam lainnya. Pengunjung biasa datang dari lokal maupun dari luar Privinsi Riau misalnya Belum mewujudkan, menumbuhkan, mengembangkan, serta meningkatkan kesadaran dan tanggungjawab akan hak dan kewajiban Pemerintah Daerah Provinsi dalam pengelolaan Warisan Budaya dan Cagar Budaya belum mengembangkan dan menerapkan kebijakan yang dapat menjamin terlindunginya dan termanfaatkannya Warisan Budaya dan Cagar Budaya. Berdasarkan fenomena diatas, maka penulis tertarik melakukan penelitian dengan judul "kewenangan Dinas Kebudayaan Provinsi Riau Dalam Pelindungan Cagar Budaya Mesjid Jami' Air Tiris”. Merujuk pada uraian latar belakang diatas, maka pertanyaan penelitian ini adalah Bagaimana Kewenangan Dinas Kebudayaan Provinsi Riau Dalam Pelindungan Cagar Budaya Mesjid Jami' Air Tiris?,

\section{METODE}

Lokasi penelitian ini dilakukan di Desa Tanjung Berulak, kecamatan Kampar, alasan pemilihan lokasi yaitu karena Desa Tanjung Berulak merupakan salah satu Desa yang perkembangannya meningkat dibidang pembangunan dinilai sangat bagus. Pendekatan yang dipakai dalam penelitian ini adalah kualitatif dengan jenis penelitian deskriptif. Hal ini mengingat penelitian lebih banyak menggambarkan suatu fenomena yang diamati dan tidak mengadakan perhitungan dengan menggunakan teknik statistic.

\section{Tabel 1.1}

Daftar nama Informen dan key informen dalam Kewenangan Pemerintah Provinsi Riau dalam Perlindungan Cagar Budaya Mesjid Jami’

\begin{tabular}{lllc}
\hline No & Informan & Jabatan & Jumlah \\
\hline 1 & Kepala Dinas Kebudayaan Provinsi Riau & Key informen & 1 \\
\hline 2 & Seksi Sejarah & Informen & 1 \\
\hline 3 & Seksi Pelestarian Cagar Budaya & informen & 1 \\
\hline 4 & Seksi Permusiuman & informen & 1 \\
\hline 5 & Kepala Desa & informen & 1 \\
\hline 6 & Masyarakat Desa Tanjung Berulak & informen & 5 \\
\hline
\end{tabular}

Sumber : Data Olahan Peneliti Tahun 2020 


\section{HASIL DAN PEMBAHASAN}

Hasil penelitian dan pembahasan mengenai Kewenangan dinas Kebudayaan Provinsi Riau Dalam Perlindungan Cagar Budaya Mesjid Jami' Air Tiris Kabupaten Kampar. Yaitu pada bab ini akan dikelompokkan menjadi beberapa sub bab yakni bab satu akan membahas bagaimana bentuk kewenangan Dinas Kebudayaan Dalam Perlindungan Cagar Budaya Mesjid Jami' dan pada bab dua akan dibahas bagaimana kendala-kendala yang dihadapi dalam perlindungan Cagar Budaya Mesjid Jami; Air Tiris. Kewenangan Dinas Kebudayaan Provinsi Riau dalam Perlindungan Cagar Budaya Mesjid Jami' Air Tiris Kewenanganm merupakan kekuasaan formal yang berasal dari undnag-undang.

\section{A. Atribusi}

Atribusi merupakan kewenangan asli yang atas dasar konstitusi (UUD), seperti halnya Cagar Budaya lainnya Mesjid Jami' Air Tiris juga memiliki norma atas dasar hukum perlindungan Cagar Budaya yang terdapat dalam peraturan Daerah Provinsi Riau Nomor 15 Tahun 2013 tentang pelestarian Cagar Budaya. Dengan adanya dasar hukum aperaturan Daerah Riau yang menjadi aturan diberlakukannya aturan-aturan yang dibuat untuk perlindungan Cagar Budaya Mesjid Jami' Air Tiris yang berda di Desa Tanjung Berulak, dapat dijadikan acuan untuk melakukan aturan-aturan yang dibuat untuk perlindungan Cagar Budaya Mesjid Jami' dapat dijadikan acuan untuk melakukan upaya-upaya promosi,pengenalan Cagar Budaya

Mesjid Jami' ini kepada laposan masyarakat baik yang ada di Kabupaten Kampar maupun diseluruh Kabupaten Kampar maupun diseluruh kabupaten/kota bahkan diseluruh Provinsi yang ada di indonesia umumnya. Sehingga dapat dipandang suatu sejarah yang sangat menarik dimata wisatawan lokal maupun manca negara. Hal tersebut bertujuan untuk meningkatkan apresiasi kalangan pengusaha atau insvektor terkait untuk bekerjasama dan menanamkan modalnya untuk menggerakkan roda pembangunan Mesjid Jami' ini agar lebih baik menarik yang memang membutuhkan biaya besar yang tidak dapat disediakan sepenuhnya oleh pemerintah.

Cagar budaya Mesjid Jami' yang ada di kabupaten Kampar sudah termasuk kedalam salah satu cagar budaya yang dilindungi dan dipayungi oleh dasar hukum berupa undang-undang yang berlaku di Indoensia, undnag-undnag yang dimaksud untuk mengatur semua aturan tentang perlindungan Cagar Budaya Mesjid Jami' yang bertujuan untuk dilestarikan dan dilindungi.Berdasarkan kutipan wawancara di atas pemerintah Provinsi Riau sudah berpartisipai dalam perlindungan cagar budaya Mesjid Jami' dalam aspek non fisik berupa penetapan pendaftaran Cagar Budaya benda tidak bergerak di Provinsi Riau yang bekerjasama dengan BPCB serta Dinas Kebidayaan Pariwisata yang ada di Kabupaten Kampar kedalam daftar nama-nama cagar budaya yang dilindungi untukm kemajuan pembangunan Cagar Budaya Mesjid Jami' agar tetap terawat dan dilestarikan sehingga tidak terkubur dengan kerusakan pembangunannya

\section{B. Delegasi}

Delegasi merupakan kewenangan dimana perannya dapat dialihkan dapat dilakukan oleh individu dalam masyarakat organisasi. Dalam hal ini personifikasi ditunjukkan kepada Dinas Kebudayaan Provinsi Riau sebagai pelaku dalam upaya perlindungan Cagar Budaya.perlindungan Cagar Budaya dibagi menjadi dua bagian yaitu perlindungan fisik dan perlindungan non fisik. Perlindungan fisik yaitu perlindungan yang dilakukan secara langsung dan dapat dilihat hasilnya, perlindungan fisik ini dpat berupa renovasi, zonasi pemugaran Cagar Budaya.dan perlindungan non fisik yaitu perlindungan yang dibukukan tidka nampak wujudnya secara langsung. Perlindungan ini dapat berupa penetapan,pendaftaran Cagar Budaya tersebut.Berdasarkan hasil wawancara Dinas Kebudayaan Provini Riau sudah melakukan perlindungan 
Cagar Budaya Mesjid Jami' dari aspek non fisik yang meliputi kgiatan pendaftaran dan penetapan Cagar Budaya Mesjid Jami’ yang ditangani oleh Provinsi Riau

\section{Mandat}

Mandat adalah kewenanganyang berasal dari pelimphan,mandat yang diberikan oleh pemrintah Provinsi kepada Pemerintah Kabupaten Kampar. Dalam hal ini dinas Kebudayaan Provinsi Riau memiliki hubungan yang sangat erat dalam hal perlindungan cagar budaya Mesjid Jami' yang ada dalam hal ini Dinas Kebudayaan Provinsi Riau memiliki hubungan yang sangat erat dalam hal perlindungan Cagar Budaya Mesjid Jami' yang ada di desa Tanjung bBerulak salah satu satunya upaya Jami' mulai dari pemberitahuan Surat Keputusan (SK) kepada Bapak Amiruddin Khatib (Bapak Udin) selaku Garim atau juru kebersihan Mesjid yang dianggarkan gajinya setiap bulan atau masyarakat kepada tokoh agama dilingkungan sekitar yang dainggap perlu.Berdasarkan kutipanwawancara bapak Amiruddin Khatib (Udin) dipekerjakan secara legal oleh Dinas Kebudayaan Provinsi Riau. Dengan adanya peran Dinas Kebudayaan dan Pariwisata tersebut dapat menambah.

\section{KESIMPULAN}

Dalam upaya perlindungan cagar Budaya Mesjid Jami’ yang ada di desa Tanjung Berilak Dinas Kebudayaan Provinsi Riau dihaapkan pada beberapa permasalahan yaitu: pengajuan proposal yang tidak rutin oleh kepengurusan Mesjid Jami' dan terbatasnya dana dan anggaran Dinas Kebudayaan Provinsi Riau serta masih rendahnya pemahaman masyarakat terhadap perlindungan Cagar Budaya. Berdasarkan ovservasi dan hasil wawancara dengan berbagai informen maka ditemukan kendala-kendala dalam kewenangan dinas Kebudayaan Provinsi Riau dalam Perlindungan Cagar Budaya Mesjid Jami’ Air Tiris yaitu

1. Pengajuan proposal yang tidak rutin dilakukan oleh pengurus Mesjid merupakan pengajuan proposal yang tidak rutin dilakukan oleh pengurus Mesjid merupakan masalah yang mendasar dihadapi oleh Dinas Kebudayaan Provinsi Riau dalam perlindungan Cagar Budaya Mesjid Jami'

2. keterbatasan anggaran dana yang ada pada Dinas Kebudayaan Provinsi salah satu kendala utama dalam perlindungan Cagar Budaya Mesjid Jami' karena satuan anggaran dalam satu kegiatan juga satuan yang menempati posisi penting diartikan juga satuan yang menempati posisi yang sangat penting dalam arti segala kegiatan yang akan dilakukan dikualifikasi dalam satuan uang

3. rendahnya pemahaman masyarakat terhadap perlindungan Caar Budaya Mesjid Jami' Air Tiris Masyarakat merupakan ujung tombak dalam perlindungan Cagar Budaya Mesjid Jami' yang berdiri kokoh di Desa Tanjung Berulak, kepedulian masyarakat berawal dari pengetahuan, wawasan dan pemahaman akan peraturan-peraturan cagar Budaya Mesjid selaku pengguna secara langsung dalam kehidupan sehari- hari

\section{SARAN}

Berdasarkan hal diatas ,maka dalam perlindungan Cagar Budaya Mesjid Jami' penulis merekomendasikan hal-hal sebagai berikut:

1. Upaya perlindungan Cagar Budaya Mesjid Jami' hendaknya melakukan perlindungan hendaknya dilakukan secara fisik dan non fisik untuk melestarikannya. 
2. Pengajuan proposal hendaknya secara rutin diajukan oleh pengurus Mesjid Jami' agar hubungan struktur social antara Dinas Sosial dan Dinas Kebudayaan Provinsi Riau dan pengurus Mesjid Jami' selaku wakil masyarakat terhadap terlaksananya dengan baik dan efektif.

3. Walaupun dengan anggaran terbatasnya Dinas Kebudayaan Provinsi Riau hendaknya menganggarkan dana untuk perlindungan fisik Mesjid Jami; kedalam renacana pembanguna jangka menengan ( RPJM) pembangunan janhgka menengah daerah (RPJMD) yang dituangkan dalam rencana kerja (RENJA).

\section{DAFTAR PUSTAKA}

[1] Ardiana Yuli Puspitasari,Eppy Yuliani (2019)"Konsep Pemenfaatan Bangunan Cagar Budaya di Kawasan Kota Lama Semarang, Jurnal Panologi.,vol.16.

[2] Dimas Widya Putra (2016) Identifikasi Kelestarian Kawasan Kota Lama Melalui Proteksi Bangunan Cagar Budaya Oleh Pemerintah Kota Surabaya, Jurnal Pengembangan Kota.,vol.4.

[3] Faridha Larashati Dewi (2016) Upaya Pelestarian Bangunan Cagar Budaya Perpustakaan Bank Indonesia Surabaya, AntounairdotNet., vol.,3.

[4] Francisca Romana Harjiyatni,Sunarya Rahardja (2012) Perlindungan Hukum Benda Cagar Budaya Terhadap ancaman Kerusakan di Yogyakarta, Mimbar Hukum.,vol.24.

[5] Khotman Annafie (2016) Kelembagaan Otonomi Khusus (OTSUS) Dalam Mempertahankan NilaiNilai Kebudayaan di Provinsi Daerah Istimewah Yogyakarta, jurnal Ilmu Pemerintahan \&Kebijakan Publik., Vol.3.

[6] Khalid Rosyadi,Mochamad Rozikin,Trisnawati,(2014)Analisis Pengelolaan Dan Pelestarian Cagar Budaya Sebagai Wujud Penyelenggaraan Urusan Wajib Pemerintahan Daerah, Jurnal Administrasi Publik.,vol.2.

[7] Muhammad Budi Sutrisno, Untung Sri Hardjianto (2016) Perlindungan Benda Cagar Budaya Terhadap Ancaman Kerusakan di Kota Lasem Berdasarkan Peraturan Daerah Nomor 5 Tahun 2014 Tentang Pengelolaan Cagar Budaya di Kabupaten Rembang, Diponegoro Law Journal., vol.5.

[8] Nurdiani (2014)Teknik Sampling Snowball Dalam Penelitian Lapangan, ComTech Camput.Math.Eng.Appl.

[9] Supratikno Rahardjo (2013) Beberapa Permasalahan Pelestarian Kawasan Cagar Budaya Dan Strategi Soluainya, Jurnal Konservasi Cagar Budaya Borobudur.,vol.7.

[10] Peraturan Daerah Provinsi Riau Nomor 15 Tahun 2013 Tentang Pelestarian Cagar Budaya Pasal 18 ayat (2) Tentang Negara Kesatuan Republik Indonesia dibagi atas Daerah Provinsi Kabupaten dan Kota atau Provinsi,Kabupaten,dan Kota diatur dalam Undang - Undang dengan memperhatikan kekhususan dan keragaman Daerah. 
[11] PP Nomor 19 Tahun 1995 Tentang Pemeliharaan dan Pemanfaatan Benda Cagar Budaya di Museum

[12] Sriayu Aritha Panggabean (2014) Perubahan Fungsi Dan Struktur BangunanCagar Budaya Kota Semarang Ditinjau Dari Perspektif Undang-undang Nomor 11 Tahun 2010,Unnes Law Jurnal., vol.3.

[13] Uni Ekowati,Wellem Nggonggoek,Susilo Setyo Utomo (2019) Persepsi dan Partisipasi Masyarakat Terhadap Peninggalan Situs Cagar Budaya Gua Jepang dan Upaya Pelestariannya, Jurnal HISTORIA.,vol.7.

[14] Undang - Undang Dasar Republik Indonesia Tahun 1945.

[15] Undang - Undang Nomor 23 Tahun 2014 Tentang Pemerintahan Daerah.

[16] Undang - Undang Nomor 5 Tahun 1992 Tentang Cagar Budaya.

[17] Volare Amanda Wirastari dan Rimadewi Suprihardjo (2012) Pelestarian Cagar Budaya Berbasis Partisipasi Masyarakat, Jurnal Teknik ITS.,vol.1. 